This article was downloaded by: [Pere, Lynne]

On: 27 July 2009

Access details: Access Details: [subscription number 912912209]

Publisher Informa Healthcare

Informa Ltd Registered in England and Wales Registered Number: 1072954 Registered office: Mortimer House, 37-41 Mortimer Street, London W1T 3JH, UK

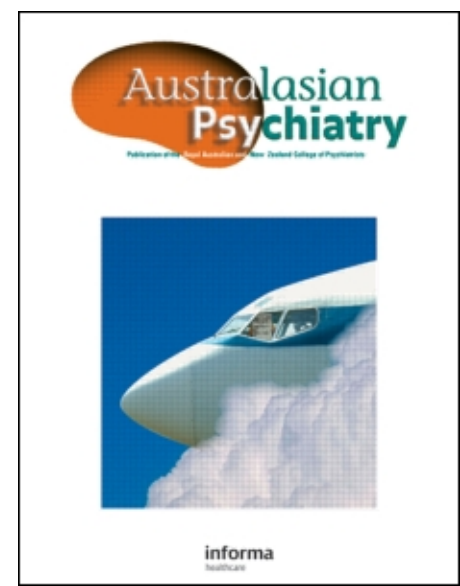

\title{
Australasian Psychiatry
}

Publication details, including instructions for authors and subscription information:

http://www.informaworld.com/smpp/title content=t768481833

\section{Creating better futures: when the theory fails and the future is no more}

\section{Lynne Pere a}

a Health Services Research Centre, Victoria University of Wellington, Wellington, New Zealand

Online Publication Date: 01 August 2009

To cite this Article Pere, Lynne(2009)'Creating better futures: when the theory fails and the future is no more',Australasian Psychiatry, 17:1,S10 - S14

To link to this Article: DOI: $10.1080 / 10398560902950502$

URL: http://dx.doi.org/10.1080/10398560902950502

\section{PLEASE SCROLL DOWN FOR ARTICLE}

Full terms and conditions of use: http://www.informaworld.com/terms-and-conditions-of-access.pdf

This article may be used for research, teaching and private study purposes. Any substantial or systematic reproduction, re-distribution, re-selling, loan or sub-licensing, systematic supply or distribution in any form to anyone is expressly forbidden.

The publisher does not give any warranty express or implied or make any representation that the contents will be complete or accurate or up to date. The accuracy of any instructions, formulae and drug doses should be independently verified with primary sources. The publisher shall not be liable for any loss, actions, claims, proceedings, demand or costs or damages whatsoever or howsoever caused arising directly or indirectly in connection with or arising out of the use of this material. 


\title{
Creating better futures: when the theory fails and the future is no more
}

\author{
Lynne Pere
}

Objective: The aim of this paper is to advance and enrich innovative thinking about mental health issues from an Indigenous perspective, through consideration of the gap between Indigenous mental health research and Indigenous mental health practice.

Key words: Indigenous mental health experience, mental health practice, mental health research, suicide.

I have become increasingly aware of the absolute importance of narrative, of authorship, and of story telling. This paper is my story. Its prose is intentionally subjective, written in the first person, to allow the reader to enter my world, to be privy to and experience my personal thoughts and feelings. ${ }^{1}$ The topic area of the paper demands this stance.

\section{MY THEORETICAL BACKGROUND}

In March 2008 I submitted an abstract to an Indigenous mental health conference with an admirable purpose of 'creating futures'. I entitled my proposed paper 'Dare to believe: an alternative approach to Indigenous mental health'. In the abstract I wrote, "whilst the importance of culture may be well recognised in mental health policy in New Zealand, listening to Indigenous understandings of mental health and taking them on board - particularly when they may not fit with traditional clinical diagnoses, systems and processes - is often overlooked".

I was about to embark on a 4 year qualitative study as part of my postdoctoral work in Australia, Canada and New Zealand - work which I stated "aims to advance and enrich innovative thinking about mental health issues from an Indigenous perspective, to inform alternative approaches to mental health policy, and to benefit mental health practice with Indigenous people". The study particularly focused on the significance of culture on meanings that Indigenous peoples from these three countries, who have experience of mental illness, impart to their 'illness'.

My postdoctoral research extends doctoral research findings that understanding mental health means looking beyond diagnoses, and recognizing that mental health experiences are not external to those diagnosed with mental illness, but part of them. Their interpretations and the meanings they attach to their personal experiences, often influenced by culture, provide alternative explanations and understandings of mental health. It calls into question the importance for recovery, of sharing the meaning behind the thoughts and ideas of Indigenous peoples with experience of mental illness that may otherwise be seen as unusual and symptomatic of illness. I suggested that my research explores the possibility that when others share the rationale - or the personal meaning - behind 'irrational' thoughts and ideas, when there is a genuine interest in a person's experience of mental phenomena, recovery improves through a greater 
sense of 'being understood' and accepted, and an increased self-worth. And I explained that although there was once much interest in psychoanalysts' emphasis on the meaning given to the experience of mental illness, this is an oft misunderstood aspect of current mental health practice, worthy of consideration.

\section{LIFE'S REALITY}

One day after I wrote that, my husband, my soul mate, and the love of my life, ended his life. On that day, my life as I knew it, ended too.

My Darling was 'my everything'. I knew everything about him. I knew the way he moved, the way he smelt, the way he thought. I knew every curve of his body, how to read his eyes, how to make him laugh. I knew what he loved, what destroyed him. I bore four of his children. We shared every joy, every tear, and every single experience of our lives for more than 20 years.

I, apparently, have expert knowledge in Indigenous mental health. I have worked within the field of Māori health for over 20 years. I trained as a nurse, managed a Māori mental health unit in New Zealand's largest mental health institution, have undertaken countless mental health focused research projects, listened to the mental health experiences of many, delivered lectures and papers to hundreds, contributed to and written numerous reports, publications and musings on the topic; indeed, I was awarded a doctorate for my investigation into the importance of cultural identity for Māori mental health. I have gained academic kudos through what I supposedly know about Indigenous mental health experience.

Yet, I could not save the person I knew best in the world - a man whose first ever involvement with mental health services was 27 days before he died, who had no clinical diagnosis, but a man who was profoundly unwell.

\section{REALITY TESTS THEORY}

Creating futures speaker Professor Tony Jorm from the University of Melbourne refers to a 'sub-threshold level' of mental illness or distress. He suggests that much of the burden of depression and anxiety in the Australian population is attributable to sub-clinical symptoms (unpublished data, 2008). I surmise that my Darling experienced a sub-threshold level of mental illness for quite a period of time before becoming acutely unwell. For the last 2 years of his life, he was sporadically and then more frequently, suicidal. These suicidal ideations were accompanied by increased anger at the world which was most often directed at those who loved him most, and decreased feelings of self-worth.

Psychoanalyst Michael O'Loughlin [speaker at Creating Futures and contributor to this Supplement] refers to secret or unspoken trauma which, left unresolved, is likely to manifest inward at the self or outward at the world. Australian feminist academic Dr Germaine Greer calls this 'rage', a "disabling mental condition that can be lethal". 2

Greer suggests that most people think suicide is an act of grief. She names suicide, however, as part of the spectrum of utterly self-destructive behaviour associated with rage, noting that "humans can live with grief but they can't live for long with rage". She explains that part of rage is self-loathing, and selfloathing also expresses itself in hostility towards those close enough to get hurt; "those who love the enraged person the most can expect the cruelest treatment". 2 Each year in New Zealand an average of 11 women and three men are murdered by their partner's overwhelming rage. ${ }^{3}$ Although we have learnt how to recognize rage in traumatized children, differentiated from tantrums, according to Greer, we are less capable of diagnosing this terminal rage in adults. ${ }^{2}$

My Darling frequently exhibited this rage. His feelings of hopelessness, loss of control, worthlessness and helplessness, incapable of articulation, were profound. They were steeped in historical, cultural and contemporary trauma, and manifested themselves in blind, thwarted rage in all its fury.

When he died, everything we knew to be the future was buried with him. Yet, here I was proposing to present a paper at a conference called Creating Futures about daring to believe in what people with experience of mental illness thought about their experiences, as an alternative approach to Indigenous mental health recovery. After all, it is much easier to listen to a psychiatrist explain their belief that your family member has an illness which means they hear, feel, smell and see things that are not in fact there, than it is to listen to that family member explain their belief that they have taken on the persona of a deceased relative who is now speaking through them. The latter of the two explanations is most often less understood.

My Darling's ancestors 'visited' him 9 days before he took his life. Many of them came. He acknowledged them each. They placed a traditional Māori cloak around his shoulders and told him with absolute clarity that everything was going to be alright. He was flooded with an unqualified, calm assurance of purpose and direction, which for the first time in a very long time gave him cause to be, and he grabbed hold of it with all his might and with total conviction. The emancipation he described in knowing, beyond all doubt, his life's meaning, enveloped him in a comfort and tranquility that carried him to an unrealized place of complete and utter peace and stillness.

My Darling was convinced that the 'visit' of his ancestors was real and true; as did I. While experiences such as this would likely be perceived as 'irrational' or delusional by non-Indigenous mental health 
professionals and symptomatic of mental illness, the 'visiting' of ancestors is more readily accepted as 'real and meaningful' by Māori and "not necessarily dubious at all". 4 It is often viewed with a degree of caution and trepidation, however, because these 'visits' are commonly known to occur prior to death. My Darling was not at all perplexed by this thought when it was raised with him by fearful family members. He did not believe this to be its purpose.

\section{THEORY INTO PRACTICE - CULTURAL MEANING}

When faced with the reality then, of putting my theory into practice, of sharing the meaning behind this experience that might otherwise be seen as a result of medication not yet stabilized at a therapeutic level, I did not hesitate. I had a genuine interest in my Darling's experience of this cultural or mental phenomenon, if that is what it is called. It was hugely significant to him, his wellbeing, and his feeling of self-worth and acceptance. And my research had shown that "understanding the beliefs that are significant to those who experience mental illness is one way of bridging a gap and reducing the anguish of being misunderstood in a hostile world": ${ }^{4}$

Simply dismissing the beliefs because they are 'delusions' offers no solace ... Delusional or not, genuine interest in a person's experience of mental phenomena, whether related to a depressed mood or an hallucinatory state, improves recovery. (p. 266)

Based on what I knew about mental health, I sincerely believed that the man I had witnessed getting progressively more and more unwell, had every chance of a full recovery. Commissioner Tom Calma, an Aboriginal and Torres Strait Islander Social Justice Commissioner and National Race Discrimination Commissioner [speaker at Creating Futures and contributor to this Supplement], is emphatic that a strong and resilient culture is one of the foundations of good health, and my research had shown that the link between wellness and belonging is an important indicator for recovery. ${ }^{4}$ Ample other evidence supports this opinion. ${ }^{5-8}$

My Darling was surrounded by supportive family, and had the most secure cultural identity of anyone I knew. He was steeped in his whakapapa (geneology), had strong, active links with his whānau, Iwi and hapu (family groupings made up of both immediate and much wider tribal members), marae and land, was steadfastly sure of who he was and where he came from, and was staunchly proud of this. In addition, he was receiving psychotherapy, and he finally had access to medication that could decrease his anxiety and depression.

\section{THEORY AND PRACTICE OF RECOVERY}

Anthony describes the recovery process as 'long-term' and 'multidimensional'. He suggests that rather than considering it dichotomously as 'recovered' versus 'not recovered', the process should be viewed along a continuum. ${ }^{9}$ Professor Rapp (University of Kansas, Creating Futures speaker), whose work on enhancing mental health recovery through client-centred methods and programs, refers to recovery as not just a process but also an outcome. One definition of recovery outcomes which focuses on the psychological dimensions of recovery emphasizes the development of new meaning and purpose in life, increased role functioning across domains such as work, social functioning, and living independence, as well as reduced symptomatology. ${ }^{9}$ The psychological outcome of having hope, self-esteem, confidence and self-determination was what I hoped and believed my Darling would regain, and through these, return to community integration.

So what went wrong? I have anguished over my need to know. My interest in research is premised by just this - a need to know why things are as they are, and how we can make them better. Now I am left with a need to know why the person I knew and loved most in the world, who I had spent most of my life with, died. How could this have been prevented? Many questions remain. And my need to know has now taken on much more meaning.

I question why, when prescribed SSRI medication for depression 22 days before his death, my Darling was not told of the known side-effect of deepening depression in its early stages of use; why the General Practitioner (GP) did not feel it necessary to pass on this information when, by his own admission, he was aware of it.

I question why a follow-up appointment was not made for him; why a GP felt it was acceptable to expect someone he had just diagnosed with depression to take it upon themselves to seek follow-up treatment; and what the clinical reasoning behind this decision is, when literature clearly recommends careful monitoring when prescribing the type of medication he put my Darling on, given the known increased risk of suicidal ideation and action. I question why, in an effort to decrease the high rate of patients not fronting for follow-up appointments, a healthcare professional would not make follow-up appointments. Does the additional financial cost outweigh optimizing patient recovery?

I question why an Indigenous man whose understandings of the world were Indigenous, whose beliefs were steeped in Te Ao Māori ('the Māori world'), whose interactions were noticeably different with Māori than non-Māori, was psychiatrically assessed alone, by nonMāori less than a month before he took his life; why 
these people found it alarming that their assessment of him being 'not at risk' of suicide turned out to be wrong; and why they felt competent to make such an assessment of someone who would have told them, as non-Māori, exactly what he thought they would want to hear.

I question why, with all the advancements we have made in health service delivery in New Zealand, the importance of culturally safe and relevant interventions that promote the need to work differently with Māori are still not recognized. Ample research and literature supports the notion that Indigenous peoples respond differently to other Indigenous peoples than non-Indigenous peoples. Although co-existing within one wider society, Indigenous and non-Indigenous perceptions and insights are frequently at variance. Our worldviews are different and when presented with the same picture, we perceive images differently. ${ }^{4} \mathrm{My}$ Darling's perception of non-Māori, was that they were very different from him. The chances of him sharing his understandings of what was going on for him with non-Māori were remote.

I question why the Crisis, Assessment and Treatment Team did not forward their psychiatric assessment to the GP, why no health professional considered it pertinent to ask the family about my Darling's state of mental health, and why they were shocked at his suicide, why they did not see it coming, when I did. This is perhaps the most distressing aspect of my Darling's interactions with health professionals in the months, weeks and days prior to his death. Neither his GP, nor the mental health team, nor the clinical psychologist treating him considered him to be at risk of suicide. Yet, not one of them checked his mental state with me - the person who knew him best in the world. I knew he was absolutely at risk of suicide and could have told any of them - had they listened.

I question why, 4 days after I buried my Darling, I received a letter from the Coroner advising me that in the unwanted autopsy process, body samples had been taken without any consultation or consent. I question how this atrocity could have occurred, and why my children were subjected to the horror of having to dig back to their father's coffin to rebury those parts of him that were taken without our knowledge. And I question whether telling my father-in-law, a respected elder, of this awful happening resulted in his sudden death 10 days later. Associate Professor Helen Milroy [speaker at Creating Futures], the only female Indigenous psychiatrist in Australia, is adamant that Indigenous people die from malignant grief. My father-in-law's grief was profound.

\section{THEORY OF THE IMPACT OF BEING MĀORI}

So, I need to know if the answer to all my questions is "because we are Māori". Certainly evidence would suggest that view could well be correct. According to one of our Māori public health physicians Dr Ricci Harris, ethnic inequalities in health in our country are most pronounced between Māori and the majority European population, and accumulating research suggests that racism, both interpersonal and institutional, certainly impacts on Māori health and inequalities in New Zealand. Work by Associate Professor Papaarangi Reid, Tümuaki of the Faculty of Medicine and Health Sciences at the University of Auckland and Bridget Robson from Te Rōpu Rangahau Hauora a Eru Pōmare at the Wellington School of Medicine, ${ }^{10}$ and others like Jim Anglem, a $K \bar{a} i$ Tahu Senior Lecturer at the University of Canterbury (unpublished data, 2008), and Dr Peter Jansen, a Ngāti Raukawa medical practitioner (unpublished data, 2006), certainly supports this probability.

Aboriginal PhD student Juanita Sherwood [speaker at Creating Futures and contributor to this Supplement] refers to compounding injury - how not having time to heal before another injury is inflicted creates a wound on top of a wound. My family is injured, and this includes my Darling. Even following his death, continued injury was inflicted on him. And we need to heal, but how?

The cultural fit of mental health professionals is a critical component of service delivery. With it, there is greater ease in developing rapport, and a greater possibility of accommodating the diversity of Indigenous peoples. In order to promote wellness, Indigenous peoples must be allowed to operate within cultural milieux which are familiar, and Indigenous mental health professionals are more likely to be able to accommodate this need. ${ }^{4}$ As noted by Ian Anderson [speaker at Creating Futures], an Indigenous medical practitioner and academic from the University of Melbourne, building Indigenous capacity in the health occupations is, therefore, fundamental to meeting Indigenous mental health need.

Dr Anthea Krieg [speaker at Creating Futures and contributor to this Supplement] emphasizes the importance of connections and relationships. Health is about sustaining these connections and relationships. Ill-health is about losing them. Relationships between health professionals and services are influenced in exactly the same way. According to Helen Milroy, for healing to occur, we have to find out where the threads are broken, and join them back together. Those threads are our connections, our families, our pasts, our futures.

It is imperative that family be part of any Indigenous mental health intervention. Māori do not function as individuals. We are all members of whānau, hapu and Iwi. When one of us presents as mentally unwell, we represent unwellness in the family. Cleveland Fagan, the CEO of Apunipima Cape York Health Council [speaker at Creating Futures], also refers to the importance of understanding this key principle of health 
reform. He asserts that members of Indigenous Australian families are not individuals, but rather members of clans, and health services need to be targeted and delivered accordingly. My Darling's level of unwellness was not restricted to him and did not impact solely on him. To focus on him without consideration of a bigger picture was remiss. He was not able to selfright. He needed us and we were struggling to self-right ourselves. We all needed help. Equally, we all could have provided information that could have helped him. To dismiss the involvement of family based on the perceived right of an individual's privacy is not only erroneous, but in my opinion, negligent.

I am well aware of the possibility of my Darling's suicide even if he had been initially assessed by Mãori mental health professionals, known the side-effects of the medication he was prescribed, and been given a follow-up appointment. However, I believe the chances of him doing so would have greatly decreased had the health professionals been talking to each other and been talking to me and others in the family. There were obviously additional contributors to this devastating outcome. Some of these factors are historical and unchangeable. Others are changeable.

\section{CONCLUSION}

What the suicide of my husband has tragically shown me is that, just as there are pluralistic explanations, all knowledge needs to be honoured in order for outcomes to improve. Despite having people genuinely interested in his understandings of mental phenomena, despite his strong cultural identity, supportive family, medication and psychotherapy, recovery was not possible when other evidence-based critical factors were disregarded. Mental health research findings, aimed at improving mental health outcomes, are futile in isolated application, and the outcome may be fatal.

Based on my experience, good mental health outcomes, not only of Indigenous peoples but of all populations, are dependent on listening to the voices and hearing the understandings of those with the experience and their families. It may be too late for my Darling. But he left behind five kids, eight brothers and sisters, nine brothers-in-law and sisters-in-law, countless aunties, uncles, cousins, nephews, nieces, great-nephews and great-nieces. And he left behind me. It is not too late for us.

\section{REFERENCES}

1. Britton V. Point of View: Pros and Cons of Narrating in First Person. 23 November 2007. Available from URL: http://writing-novels.suite101.com/article.cfm/writing_in_ first_person (accessed 20 October 2008).

2. Greer G. The rage epidemic. 2 August 2008. The Sydney Morning Herald. Available from URL: http://www.smh.com.au/articles/2008/08/01/1217097533898.html (accessed 20 October 2008)

3. Goodyear-Smith F. Recognising and responding to partner abuse: challenging the key facts. The New Zealand Medical Journal 2004; 117: 1202. Available from URL: http:// www.nzma.org.nz/journal/117-1202/1074/ (accessed 20 October 2008).

4. Pere L. Oho Mauri: Cultural Identity, Wellbeing, and Tāngata Whai Ora/Motuhake Unpublished doctoral thesis, Massey University, Wellington, Aotearoa/New Zealand, 2006

5. Cherrington L. A Comparison Study of the Presenting Symptoms Between Māori and Pākehā Patients Diagnosed with Schizophrenia. Unpublished master's thesis, Massey University, Palmerston North, Aotearoa/New Zealand, 1994.

6. Durie MH. Māori Cultural Identity and its Implications for Mental Health Services. Palmerston North, Aotearoa/New Zealand: Massey University, Department of Māori Studies, 1994

7. Pere RT. Ako: Concepts of Learning in the Māori Tradition. Monograph. Wellington, Aotearoa/New Zealand: Te Kohanga Reo National Trust Board, 1982.

8. Pere RT. Te Wheke: A Celebration of Infinite Wisdom. Gisborne: Ao Ako Global Learning New Zealand Ltd, 1991

9. Anthony W. Foreword. In Davidson L, Harding C, Spaniol LeR, eds. Recovery from Severe Mental IIInesses: Research Evidence and Implications for Practice, Volume 2 (pp. xv-xvii). Boston University: Center for Psychiatric Rehabilitation, Sargent College of Health and Rehabilitation Sciences, 2006.

10. Robson B, Harris R. Hauora: Mãori Standards of Health IV. A Study of the Years 20002005. Wellington: Te Rōpū Rangahau Hauora a Eru Pōmare, 2007. 